difference arises from the initial comparison of the national prototypes with the Sèvres working standards, it would correspond to an error of $0.56 \mu$ between the British and German prototypes. But this supposition has recently been shown to be unfounded. The prototype No. 16 of Great Britain and No. 18 of Germany have since been returned to Sèvres, and with the obliging collaboration of a metrologist from the N.P.L., have been very carefully compared one with the other. The result showed, within about $0.06 \mu$, the same difference that we attributed to them previously.

Albert PÉrard.

Sevres.

May 24.

1 NATURE, 135, 459 and $496 ; 1935$.

- "La Création du Bureau international des Poids et Mesures et son Euvre". Paris : Gauthier-Villars, 1927, p. 259.

s"Procès-Verbaux des séances du Comité international des Poids et Mesures", Deux. série, 15, 30; 1933.

"See Ch.-Ed. Guillaume, "Ĺes Récents Progrès du Système métrique", pp. 14 and $15 ; 1934$.

M. Perard's justification of the metrologist's claim of being able to compare two line standards with an error not exceeding $\pm 0 \cdot 2 \mu$ is based entirely on the degree of concordance observed in practice when large numbers of readings are taken in all possible positions. Equally so, we find when we analyse the purely interferometric data for the number of waves contained in an optical gauge of a metre length, the concordance between the individual results is even more striking.

Michelson has expressed the opinion ${ }^{1}$ that if the standard metre had been an optical gauge instead of a line standard, the accuracy of the wave-length determination could be increased five-fold. Sears and Barrell ${ }^{2}$ estimate that the overall probable error associated with the optical measurement is $\pm 0.016 \mu$, while the average accuracy of repetition in the measurement of line standards is taken to be of the order of $\pm 0.25 \mu$.

Unless the difference between the values of Kösters and of Sears and Barrell can be ascribed to uncertainties regarding the lengths of the line standards, one is driven to the conclusion that the discrepancy is due to a lack of symmetry in the hyperfine structure of the red cadmium source. With such asymmetry, the value obtained for the wavelength is an oscillating function of the path difference in the interferometer. This effect is much more pronounced with the Michelson instrument, or the Twyman and Green modification of it as used by Kösters, than with the Fabry-Perot interferometer employed by Sears and Barrell. The higher the effective number of reflections, the more closely does the interference fringe correspond to the real intensity distribution of the spectral line itself. Sears and Barrell used plate separations of 1/12th and 1/9th metre as basic units and were not able to detect a measurable difference in the wave-length value.

Hence, in spite of M. Pérard's assurances, there still remains the possibility that the experimental error in line standard comparisons may in reality be two or three times larger than his estimate.

King's College,

W. EWart Williams.

Strand, W.C.2.

June 18.

1 "Studies in Ontics," p. 54.

Phil. Trans. ,233, $173 ; 1934$

\section{Origin of Tektites}

GLASSY particles weighing between approximately a gram and occasionally a hundred grams have been found at several widely separated places on the earth's surface. The explanation of the origin of these natural glass particles, known as tektites, is complicated by the series of peculiar forms which they exhibit and the size of the areas over which they are found. They have been collected from each of the States in Australia, and because of this continental distribution are frequently called Australites. Several theories of their origin have been advanced and discussed in NATURE, vols. 131 and 132, 1933. Dr. L. J. Spencer and others suggest that the tektites are 'aerial fulgurites', the post-impact result of a great meteorite striking the earth in a region of sandstone or desert sand. Comparison is made with the silica-glass from the meteor craters at Henbury and Wabar. The main difficulty in accepting their theory is the wide distribution of the particles wherever they are found. The W. H. C. Shaw collection of Australites was made over a region of 30,000 square miles on a "monotonous limestone plain" on the southern shore of Australia". Furthermore, Fenner points out that the region is "without any siliceous rocks whatever"; hence a fulguritic origin for these Australites appears to be impossible.

Another theory assumes that they were originally extra-terrestrial bodies and that at the time of a meteoritic passage through the earth's atmosphere they became liquid from the frictional heat (Michel, Suess, and others)*. As they cooled, the combination of air resistance and some rotational motion of their own caused them to take on the lens, tear-drop, or dumbbell shapes which are observed ${ }^{2}$. There are several theoretical difficulties with the possibility of such a shaping process, as well as the observational objections discussed below.

There are numerous bodies which are known to have descended through our atmosphere from interplanetary space. These objects comprise three classes of meteorites: stones, stony-irons and irons. The irons show a peculiar crystalline structure, known as the 'Widmanstätten figures', which disappears when heated above $850^{\circ} \mathrm{C}$. The presence of these figures to within a few millimetres of the surface of the iron meteorites indicates that they were not heated to this temperature during their brief meteoric flight. The stones also show no internal indications of having been heated to this temperature. Further, the melting point of Darwin glass, a form of tektite, is about $1,400^{\circ} \mathrm{C.}^{3}$; it is composed very largely of silicon dioxide (about 87 per cent $\mathrm{SiO}_{2}$ ) and its coefficient of thermal conductivity is about $0.002 \mathrm{cal}$. per cm. degree sec. (fused silica, glass and sandstone). The coefficient of thermal conductivity for iron is about $0 \cdot 10$ in the same units. Hence we see that a lower temperature is required to affect the iron meteorites than to melt the tektite, and that the rate of heat transfer is about fifty times greater for the iron meteorite than for the tektite; yet the iron meteorites give no evidence of having been heated to an internal temperature $\dagger$ of $850^{\circ} \mathrm{C}$. It therefore

* The combustion theory of Iacroix appears artificial : the reartion suggested probahly could not occur during a meteoric flight, as the meteoric phenomenon is now interpreted.

+ A low internal temperature for iron meteorites in flight through the atmosphere is assumed as the result of the 'ablation' (liquification and immediate removal) of the heated surface. This process is generally believed to absorb most of the heat of the atmospheric resistancet. freshly fallen meteorites are seldom described as being more than "milk warm". 